\title{
Encouraging More Women Into Computer Science: Initiating a Single-Sex Intervention Program in Sweden
}

\author{
Gerd Brandell, Svante Carlsson, Håkan Ekblom and Ann-Charlotte Nord \\ Lulea University of Technology, Sweden
}

\begin{abstract}
The process of starting a new program in computer science and engineering, heavily based on applied mathematics and only open to women, is described in this paper. The program was introduced into an educational system without any tradition in single-sex education. Important observations made during the process included the considerable interest in mathematics and curiosity about computer science found among female students at the secondary school level, and the acceptance of the single-sex program by the staff, administration, and management of the university as well as among male and female students. The process described highlights the importance of preparing the environment for a totally new type of educational program.
\end{abstract}

\section{Introduction}

The fields of computer science and computer engineering are dominated by men. In Sweden, this is more accentuated than in many other countries. The percentage of women admitted to computer science and engineering (CSE) programs at Swedish universities is extremely low and has varied between 5 and 10\% during the period 1985-1995.

At the Luleå University of Technology about 1000 students have been admitted to a masters program in CSE since it started in 1982 . Only $70(7 \%)$ have been women, and the percentage has decreased over the years. This gender imbalance prompted the radical idea of starting a CSE program which only admits womenthe first single-sex program at the university level in Sweden. The idea was radical not only because the program would be the first of its kind, but also because it was in conflict with general opinion and official policy in Sweden that there should be no special educational provisions for men or for women.

Our basic hypothesis for the introduction of the single-sex program was that more women in CSE would benefit the field of information technology. We believed that more women working in the computer industry would mean that new perspectives would be introduced, thus influencing the design of systems and the choice of applications. We also believed that there were many women who could contribute to these developments, including women who had not chosen to specialise in science and mathematics in secondary school. CSE education in Sweden is heavily based on mathematics. Hence, it was considered important to attract women who had been discouraged from specialising in CSE by science rather than by mathematics. We thought this group was too large to neglect.

Another hypothesis for the program's introduction was our belief that women are repelled by the masculine culture surrounding computers and by the prospect of being in a minority in computer education courses. A single-sex program, we 
believed, would boost their confidence to begin a course of study in CSE. At the same time we were afraid that this "special treatment" would be discredited by future employers, other students, and by the women themselves. Therefore, we felt that it was very important to demonstrate that the academic level of the program was the same as that offered to students in the regular course.

In this paper the process of gaining acceptance for the single-sex CSE program is described. A crucial element involved the administration of a survey questionnaire to female students in upper secondary schools. The findings revealed substantial interest in a program of this kind and helped to convince other important groups that the approach was worth trying. Also described are the specific changes made to accommodate women's needs, as well as some of our experiences of the program's first two years. It is important to point out that the single-sex program is an intervention in progress. Thus a final evaluation of its success cannot be provided. Instead, the current status of the project is presented and ideas for future research are suggested.

\section{Background}

\section{The Swedish Education System}

The Swedish upper secondary school (Grades 10-12) is presently undergoing major reform. We anticipate that this will have minimal impact on the gender balance of CSE courses. The education system described below is that which was in place when our single-sex program was introduced.

Of all students completing compulsory schooling (Grade 9), 98\% enter upper secondary school. Programs of study in the upper secondary level prepare students for tertiary studies and/or occupations in specific areas. There were several different upper secondary school programs and each consisted of a large number of compulsory courses. Only a few were directly aimed at preparing students for tertiary studies. The most popular ones were social studies, science, technology and economics. Only'two, the science and technology programs, gave direct access to university level engineering and science courses.

Engineering education at the university level is organised into two different programs: the masters program which is of four and a half years duration, and a shorter program of two or (more often) three years of study which leads to a bachelors degree. Students are admitted to all engineering programs strictly according to their grades from upper secondary school.

The number of students choosing the science program in upper secondary schools is less than the number of places available at the university level for students with that background. About $20 \%$ of all students entering upper secondary school choose the science or technology programs, while the demand from universities is estimated to be about $30 \%$. The choice of upper secondary school programs is also strongly gendered. Only about $25 \%$ of the students in the science and technology programs are female. 
The lack of students studying science and mathematics at an advanced level at upper secondary school is the reason why a bridging year is now offered to all students (both male and female) at most Swedish universities. To qualify, students require a background in the social studies or economics programs with a certain level of mathematics (lower than that offered in the science program). The bridging year aims to provide students with the required knowledge of mathematics, physics and chemistry to proceed with tertiary studies and guarantees entry into a science or engineering program. This bridging year was first introduced at the Luleå University of Technology in the late 1970s. On a national basis about 2000 students enter the bridging program every year.

\section{Women in Engineering and Single-Sex Settings}

Engineering education and engineering professions are strongly sex biased. This is true in Sweden, as well as in most other countries. Only $13 \%$ of all professionally active engineers in Sweden are female, and only $20 \%$ of all engineering students. Substantial efforts have been made during the past fifteen years to encourage more Swedish women into science and engineering. These efforts (and other factors) have resulted in an increase in the proportion of women among the newly registered engineering students in masters programs. But the rather rapid increase from $14 \%$ to $20 \%$ in the early 1980 s has, over the last ten years, slowed to near-stagnation: $20 \%$ in 1985 to only $22 \%$ in 1994 .

Research has been undertaken to increase understanding of the social, pedagogical and psychological aspects of the situation for women in science and engineering. A recent study from the Netherlands, for example, has shown that females encounter obstacles of various kinds including less encouragement and less support than males, but that they still have equally good examination results (Overdijk, 1996). In computer science and engineering the picture is even more biased against females than in science and engineering education in general. An overview of the situation for women in computer science and an annotated bibliography are found in Spertus (1991). The situation for female students in engineering courses in the Nordic countries has been investigated (see Kvande, 1984; Kolmos, 1989; Göransson, 1995; Hanström, 1994). However, none of the studies involved direct coupling to concrete interventions. The KIM-project in Stockholm involved actions aimed at a more gender-inclusive mathematics education at the university level (Jacobsson \& Elvin-Nowak, 1994) with the longterm goal of attracting more women into higher levels of study.

In Sweden, coeducation has been the only education setting for over thirty years. Former single-sex schools were transformed into coeducational ones in 1960 when nine-year, compulsory comprehensive schools were introduced. At that time, coeducation was viewed as a means to improve gender equality and as the only system which would conform to the basic values of a society with equal rights for men and women.

In many countries, coeducation and single-sex education have existed side-byside and continue to exist at all levels including the tertiary level. In the USA, female colleges have a long history, many of them with very good reputations. Discussions of the advantages of single-sex education over coeducation have been 
ongoing and there has been much research in this area. There have been many reports showing that women from women's colleges are more likely to be successful in their academic careers than women from coeducational institutions (e.g., Tidball, 1973, 1989; Tidball \& Kristiakowsky, 1976). This has been attributed to the greater self-esteem and less gender-stereotypic career aspirations of women graduating from women's colleges. The importance of female academic staff serving as role models has also been put forward as an explanation (see American Association of University Women, 1992).

As a direct means to promote mathematics for female students, single-sex settings are not uncommon outside the formal educational structure. Examples include the Summermath program for school-aged students (Morrow \& Morrow, 1995 ) and the summer school for female graduate students in mathematics at the Institute for Advanced Studies at Princeton (Karen Uhlenbeck, personal communication, September 1996). Similar programs are also found in Sweden.

Within the educational structure, single-sex interventions are less common. One example is a new Canadian school for girls (Grades 4 to 12) which opened in 1993 (Moore \& Goodie, 1995). There the teaching is based on feminist pedagogical strategies. A systematic discussion of intervention strategies for encouraging women into mathematics is presented in Leder, Forgasz and Solar (1996). However, we were unable to locate studies of single-sex programs at the tertiary level in which the single-sex setting was introduced into a coeducational environment.

\section{The Single-Sex Program at Luleå}

\section{Gaining Support for the Program}

Since the late 1970s, the Luleå University of Technology has been somewhat more successful in recruiting women into engineering than other technical universities in Sweden. There are several reasons: the structure and content of some of the programs, special initiatives towards female students, a favourable social climate, the bridging year, and the pedagogical methods used at Lulea which include lectures in small groups and relatively more project work. However, these factors have not had much effect on the CSE program in which less than $5 \%$ of the 60 newly admitted students each year are female.

In 1994 a new program, aimed at improving the gender balance in CSE courses, was devised. The program was designed with the following characteristics:

- It would be directed towards students from upper secondary school social studies or economics programs and would require a strong interest in mathematics. No previous knowledge of computers would be necessary.

- The goals of the program would coincide with those of the pre-existing CSE program, but some courses would be specifically designed. One aim would be to provide a comprehensive view of the area and to introduce applications in the first year of study.

- The first two years of the program would be single-sex. Remaining courses would revert to the coeducational setting of existing programs. At graduation, all CSE students would have the same skill levels. 
- Some courses would be problem-oriented. Teaching methods which encouraged or demanded cooperation would be used.

- Compared with the regular program, students would be more involved in decisions about content and lecturers would engage in more discussion with students both inside and outside classes.

- There would be several options for gaining a degree in computer science or engineering. After one-and-a-half years students would choose to complete one of the various bachelors or masters programs which would take three-, four-, or fiveand-a-half years in total.

Surveys were conducted among female and male engineering students at the Luleå University of Technology in 1992 and in 1994. Students were interviewed in 1993 and 1994. The aims were to gather ideas on how to improve the educational program to meet female students' expectations and improve their situation (Brandell, 1996). The development of the single-sex CSE program was greatly influenced by what was learnt from the project. Of crucial importance, it seemed, were the processes by which reforms and actions taken are legitimated and support for them gained from various groups including other students, academic staff (including those not directly involved), administration and management. The processes undertaken to gain support for the program and get it started are described next.

A survey of female secondary school students. To test our hypotheses for introducing the single-sex CSE program, and to see if there was sufficient interest in the group to be targeted for entry, 176 females in the final year of the social studies or economics programs of three upper secondary schools in the region were surveyed. We presented them with the proposal for the new program and investigated their reactions (Carlsson \& Nord, 1994). To our surprise the single-sex approach was widely accepted by these young women. There were only four out of the 176 surveyed who strongly disapproved of the idea. Several students pointed out that all-girls classes may not be a good idea in general, but for the important area of computer science education in particular, it seemed worth trying during the introductory phase. We believed that the acceptance of a single-sex initiative in the case of CSE supported our hypothesis that women can be repelled by the masculine culture surrounding computers.

Even though these students had not chosen to study sciences and mathematics at the secondary level, $40 \%$ of them indicated a liking for mathematics. This suggested that a large group of young women might abandon science and technology at the secondary level because of the sciences rather than because of mathematics. When we asked if the students were interested in applying for the program, 53\% answered that they were. This seemed an amazing result considering that there are so few women actually studying university level mathematics and computer science. Of the students indicating an interest to apply, about half also thought mathematics was interesting $(28 \%$ of all students surveyed). Since there are about 20,000 female students completing the social studies program at upper secondary school each year, these results encouraged us to believe that we might get a sufficient number of high quality applicants for the program. Our belief that there were many women not choosing science and 
mathematics at school who could contribute to developments in information technology appeared to be vindicated. Our hypothesis that women are reluctant to be in a minority was not supported, however. Responses showed that $68 \%$ would not hesitate to apply for an interesting educational program which might have very few women; the rest indicated that they would hesitate, but then apply.

The students were also asked if they would consider studying for a masters degree or a bachelors degree in engineering. Only $10 \%$ said "yes" to a masters degree and $13 \%$ to a bachelors degree. "Maybe" was the response of $53 \%$ to a masters degree and $56 \%$ to a bachelors degree. That so many of the students were ambivalent convinced us that we had to emphasise that there were several ways of getting a degree after the first two years of study. This was important in our recruiting.

The support of key groups. The results of the survey convinced us that we would get enough students to fill a class of 30 in the program. This was the first step in getting support from some of the key groups at the university. Indeed, we believe that the results of the survey were the most important reason for the acceptance of the program.

The first group to provide support was the faculty whose members taught the major subjects of the program. To get that support we had to emphasise that the existing CSE program was good, and with minor changes it would be even better for both women and men. After establishing that it was not the fault of the lecturers that so few women came to the university we were able to discuss how to improve the situation. Before the survey the major objection from this group had been that women did not want to be in a single-sex group. They had come to this conclusion after discussions with women often their own age. After having been confronted with the results of the survey from the young female students at the secondary level they all agreed that the idea was worthwhile.

Next we needed the support of the few female students in the regular CSE program at Lulea. They were very positive about attempting to increase the number of women in their field. As with the lecturer group, there was some concern that women did not want to be involved in a single-sex program. It is likely that they felt this way because they had chosen to study information technology and did not feel that being in an area with few women was a problem. However, we had also observed that their awareness of gender issues had increased with time in the CSE program.

After gaining the support of the female students we turned our attention to the male students in the CSE program. From our experience of a project in the Department of Mechanical Engineering at Luleå University, we knew that negative reactions were to be expected from students who find special treatment for women to be wrong in principle. In order to avoid new students encountering such reactions, we wanted to check whether we had the support of the great majority of students. We decided to discuss the new program with the students in their classes of approximately 30 students. They were very supportive of the goal of increasing the number of women in the field but perhaps not as enthusiastic as the females. In many respects, many of the comments we received were similar to those from the female students. There was some concern that the program would not be fair to 
males with a secondary school social studies background nor to females with a science background. After some discussion, however, the general opinion was that the idea was worth trying since the number of women in the field needed to increase.

The most difficult groups to convince were the administration and management of the university. With the support of staff and students we were finally able to convince them that we should start the first single-sex program in Sweden. The university board had included as an action point, the need to increase the number of females in Computer Science and Engineering. This helped our case greatly. After some initial resistance we gained support for our ideas. The university decided to start the new program in August 1995.

\section{Preparing for the Program}

The second phase of introducing the program involved preparing the lecturers to have a women-only class, and to recruit students to the program. For the lecturers we arranged seminars on gender issues in general, and discussed the differences in male and female ways of expressing and behaving in particular. We also arranged a two-day workshop with most of the lecturers of mathematics and computer science, and also some lecturers of physics and chemistry. At this workshop we discussed how to deal with the new situation and how to avoid some of the situations which had occurred in the past. For many lecturers, including those not directly involved in the program, this increased their awareness of gender issues. We believed that all our students would benefit from the introduction of the new program.

The process of recruiting students was greatly helped by the fact that something new was being started. It was thus possible to get nation-wide media attention, and most student counsellors were alerted to the new program. Brochures were sent to all final-year female students who would be eligible for entry because of the secondary level specialisations they were taking. In all our publicity material, we strongly emphasised the fact that this educational program was only suitable for women who really liked mathematics and could picture themselves as computer scientists. We pointed out that the common image of a computer scientist was false, and that the job involved a lot of cooperation and social interaction.

As a result of the preparation we had undertaken, 129 women applied for entry into the new CSE program. This was more than the total number of women accepted to all CSE programs in Sweden in a typical year. Our efforts also resulted in the students who started the program feeling that they had been welcomed into the university by male students, lecturers, the administration and management.

\section{Starting the New Program}

The academic content of the new program was, to a very large extent, set from two other programs, the bridging year and the ordinary CSE program. During their first two years at the university, the female students in the new program 
essentially have to learn what students with the same background learn during their bridging year and the first year of the regular CSE Program. There is also some room for new approaches.

Mathematics. At the basic level of engineering education, mathematics traditionally serves as a filter to select students who are not suited for further studies (Hacker, 1983). This role of mathematics is less emphasised at Luleå University of Technology, possibly because the university generally recruits a wider group of students than is traditional in Sweden. In any case, mathematics is still regarded as the key subject since it sets the foundation for future studies. Therefore, any major educational reform of the CSE program had to involve mathematics.

During the first two years of the ordinary four-and-a-half year CSE program, students take mathematics, computer science and some basic engineering courses. Mathematics and applied mathematics form about half of the content of the first part of the program. There are compulsory courses in calculus, differential equations, linear algebra, discrete mathematics, linear systems, signal analysis, control theory and algorithms. During the last two years of the program students can choose between different specialisations in computer science, computer engineering or applied mathematics. These specialisations prepare students for graduate studies in the selected area.

The new program's first courses in mathematics cover part of the same content as in the bridging year-that is, algebra, trigonometry and calculus at the secondary school level-and make it possible for these introductory mathematical courses to be regarded as an integrated two-year course. The literature used in the CSE program is introduced after one semester. This is a more rational way of studying calculus, which allows students more time for studying other subjects. Some discrete mathematics is taught in connection with the programming course. The aim is to integrate the two subjects and hopefully give a more comprehensive view of the areas of mathematics and programming.

As for the teaching approaches used, lecturing is restricted. Students are encouraged to discuss mathematics problems in peer groups and to use a cooperative learning style. To make this possible, the tables in the classroom are put in fan shaped groups so that three or four students sit together, facing each other and the blackboard at the same time. This peer group method and the co-operative learning style adopted was developed and used in other mathematics courses at Luleå (Dunkels, 1996).

Research methodology is one course which is taught using non-traditional approaches. One part of this course consists of experimental methods and is delivered by the physics department. Experimental work and problem-solving are combined with relevant theory about experimental design. The other part of the course involves mathematical modelling. Students work in groups and are trained to build mathematical models by solving open-ended problems formulated in nonmathematical language. The assessment is based on oral and written reports, aimed at training students in communication skills. Videorecording is used to enable students to analyse and improve their oral presentations. All engineering students take this course which has been developed over many years. 
Computer Science. In computer science a new course has been designed. It begins in the first week of the semester with an introduction to computers. Students use word processors, electronic mail, world wide web, etc. The main part of the new course is devoted to programming, but many other topics are also included. For example, there are lectures and exercises on human-computer interaction, lectures on the historical and philosophical base of computer science and visits to computer companies. The students also work on a small project to find interesting applications of computer techniques.

Other subjects. During their second year, students are given a basic course in electronics, which uses a problem-based learning approach. In the laboratory students encounter a house with empty rooms into which they are supposed to install electrical equipment. As they proceed, they also learn the theory related to the problems they come across.

A number of smaller course changes have also been introduced. For example, in the chemistry course there is some computer-based teaching, mainly in connection with laboratory work. Many of these changes stem from student suggestions made at regular meetings with the steering committee.

Role models. We believe that it is important for female students to have female role models. The programming course is mainly taught by female lecturers who have shown great interest in developing a course suitable for the group. The twoyear mathematics course was designed by a female lecturer and many of the lecturers delivering the course have been women. Furthermore, female computer engineering graduates from Lulea have visited the class, giving their views of the profession and sharing their personal experiences. The visits were much appreciated by the students.

\section{Experiences From the Program}

When the new program started in 1995 there were 129 applicants for the 30 places. At that time, admissions were decided locally and students also had the opportunity to apply for other programs. This led to a tedious admissions process resulting in 25 students being admitted. The following year, admissions were decided centrally for all universities in Sweden. Applicants had to rank their choices and 64 had the new program as their first choice. This was a ratio of 2:1 first choice applicants per place, among the highest at the university. It should be noted that in contrast to the previous year, there had not been a special campaign to advertise the program.

Four students from the first cohort of the new program have left the course; six students from the second group have left. These numbers are not high compared to other similar programs. The main reasons the students had left were that the content had not been found sufficiently interesting and the mathematics and computer science courses were considered too hard. The departures made us even more aware of the importance of stressing the fundamental role of mathematics when publicising the program. We want to attract students who are more interested in the program than in the single-sex idea. 
On the whole, the students have done well in their studies. The average number of credits gained by the first cohort during their first year was 33.6 out of a possible 40 . For the first group we had difficulties with the programming course and only $14 \%$ passed the first-year test. In contrast, the result for the second cohort was a pass rate of $54 \%$.

Of the 21 students remaining in the first group, 17 chose to continue in the CSE masters program. The other four students (including the two oldest students) have already started a shorter program in Computer Science and Engineering. They will graduate after three or four years in total. There are 10 women among the 36 students in their new class. The four students have claimed that they have not encountered any difficulties in their new program during the first five months.

\section{Continuation of the Single-Sex Program}

A critical point in the new women-only CSE program will occur when the all female group is merged with the regular CSE group. We anticipate some problems but have also taken preventative actions. First we have ensured that the final examinations before the merger are identical for both groups. We have tried to prepare students in both groups for the merger through information and social activities. The biggest problem we anticipate is that the women from the new program may be regarded with suspicion, since their educational background is different. The best way to overcome this, we believed, was to provide the women with a solid academic foundation. They should be able to demonstrate that they are as good as the others.

With the participation of more women, we hope that the educational atmosphere will be enhanced. By having a large female group in the class we expect students to have different demands on the educational program and on the environment than when the classes were almost exclusively comprised of males. We believe that this will be beneficial for students of both sexes.

Our intention is that the single-sex program should only be a temporary solution to the problem of too few women in CSE. When there are sufficient women in the regular CSE program, there will no longer be a need for it. When that occurs the program will probably become coeducational. However, we do not expect this to happen within the next few years. Therefore, we have ensured that the single-sex CSE program is an accepted part of the Lulea University of Technology's regular educational program offerings. Now it may be almost as difficult to stop the single-sex program as it was to introduce it. We have reached a point where the program is no longer the concern of a only few enthusiastic people, but can survive without them.

\section{Conclusions and Future Research}

We have described how a single-sex program in computer science and engineering, heavily based on applied mathematics, can be introduced into an education system without any tradition in single-sex education. A number of unique circumstances interacted to make this possible. For instance, our university is relatively new and there is an open-minded approach to new ideas. Some of the 
most active people arguing for the program held key positions at the university. The political climate also seemed ready for an experiment of this type. Some of our findings from the process of introducing the program appear to be of general interest. They can be summarised as follows:

- There was much interest in mathematics among Swedish females at the secondary school level who had not chosen science and mathematics. This suggests that there is a large pool from which to recruit more women into mathematics and applied mathematics.

- Even though general opinion in Sweden is opposed to single-sex programs, there was strong support for a single-sex program in the important area of information technology. We believe that it is mainly the masculine culture surrounding computers that repels many girls from studying related topics. By having a female-only group, women may feel that they can create their own culture around computers. Setting up the single-sex program also signalled our belief that women are suited to careers as mathematicians or computer scientists.

- It is extremely important to prepare the environment for a drastically different educational program. If we had allowed students to encounter the reactions we heard during the preparation phase, we strongly believe that the program would not have been as successful. At this point we feel that the program has the support of everyone including staff, other students and local industry.

- Attempts to improve gender balance have a much better chance of long-term success if the ideas can be adopted and integrated into the local educational system. It will then no longer only be the concern of a few very enthusiastic individuals.

The first students will graduate from the program by the end of the year 2000 . At that time six groups of students (about 175 students) will have been admitted into the program. Not until then will it be possible to compare the educational outcomes of students from the new program with those of students from the regular CSE program. We know that, to the present time, the results of students in the new program are comparable with those of the other students. Over time, we believe that our efforts will help to improve the gender balance in the fields of computer science and engineering.

In future, we would like to evaluate the new program and the initial goals we had for it. In particular, we would like to gather knowledge about the experiences and views of the female students and compare them with those of the female and male students who took the regular CSE program. It would be of interest to determine whether the two groups of students differ in views on computer science and its role in society, on the gendering of computer science and technology and on the educational program for CSE and its quality.

Later, it should be possible to follow the female students from the single-sex program as professionals and to investigate whether they get and/or choose the same kinds of jobs and careers as male computer scientists. Mörtberg's (1997) research on female computer and systems engineers in Lulea used in-depth interviews and would serve as valuable background. In her dissertation, Mörtberg (1997) discussed and interpreted the narratives of these women, the choices they made, the possibilities they had to negotiate their situation, and their understanding of technology and the culture of technology. 
Finally we would like to encourage those with good ideas about improving the gender balance in science and engineering to try them out. We are willing to share our experiences, and we know that we have inspired other Scandinavian universities to make changes to their educational programs.

\section{References}

American Association of University Women (1992). How schools shortchange girls. Washington DC: AAUW Educational Foundation.

Brandell, G. (1996). Gender in engineering education. Luleå, Sweden: Luleå University of Technology, Centre for Women's Studies.

Carlsson, S., \& Nord, L. (1994). Fler kvinnor till datateknik (More women to computer engineering, in Swedish) (Tech. Rep. No. 1994:22 T). Luleå, Sweden: Luleå University of Technology.

Dunkels, A. (1996). Contributions to mathematical knowledge and its acquisition. Doctoral dissertation, Luleå University of Technology, Luleå, Sweden.

Göransson, A. (1995). Kvinnor och män i civilingenjörsutbildning (Women and men in engineering education, in Swedish). Gothenburg, Sweden: Chalmers University of Technology, Pedagogiska enheten vid FoUbyrån.

Hacker, S. (1983). Mathematization of engineering education: Limits on women and the field. In J. Rotschild (Ed.), Machina ex dea, Feminist perspectives on technology (pp. 38-58). New York: Pergamon Press.

Hanström, M. B. (1994). Studiemiljö och jämställdhet på Kungl.Tekniska Högskolan (Study environment and equity at The Royal Institute of Technology, in Swedish), (Tech. Rep. TRITA -FL-4223). Stockholm, Sweden: Royal Institute of Technology, KTHs jämställdhetsråd.

Jacobsson, C., \& Elvin-Nowak, Y. (1994). Kvinnor i matematiken (Women in mathematics, in Swedish). Stockholm, Sweden: Council for the Renewal of Undergraduate Education.

Kolmos, A. (1989). Kön og viden i ingeniöruddannelsen (in Danish) (Report No. 28). Aalborg, Denmark: Aalborg University Centre.

Kvande, E. (1984). Kvinder og högere teknisk utdanning (in Norwegian). Trondheim, Norway: IFIM.

Leder, G. C., Forgasz, H. J., \& Solar, C. (1996). Research and intervention programs in mathematics education: A gendered issue. In A. Bishop, K. Clements, C. Keitel, J. Kilpatrick, \& C. Laborde (Eds.), International handbook of mathematics education, Part 2 (pp. 945-985). Dordrecht, Netherlands: Kluwer.

Moore E., \& Goodie D. (1995). The Linden School: A Women-centred school. In H. MacKinnon (Ed.), Encouraging gender equity: Strategies for school change (pp.34-39). Ottawa: Human Rights Research and Education Centre.

Morrow, C., \& Morrow, J. (1995). Connecting Women with Mathematics. In P. Rogers \& G. Kaiser (Eds.), Equity in mathematics education: Influences of feminism and culture (pp. 1326). London: Falmer Press.

Mörtberg C. (1997). "Det beror på att man är kvinna..." Gränsvandrerskor formas och formar infromationsteknologin. Doctoral dissertation, Luleå University of Technology, Luleå, Sweden. (In Swedish)

Overdijk K. (1996). Women studying science and technology: How do they succeed? Achieving the four E's: Education, employment, equality, empowerment. Contributions to the 8th International conference on gender, science and technology, volume one (pp. 567-578). Ahmedabad: SATWAC Foundation.

Spertus, E. (1991). Why are there so few female computer scientists?, (Tech. Rep. No AITR-1315). Cambridge, USA: MIT Artificial Intelligence Laboratory. 
Tidball, M. E., \& Kristiakowsky, V. (1976). Baccalaureate origins of American scientists and scholars. Science, 193, 646-652.

Tidball, M. E. (1973). Perspective on academic women and affirmative action. Educational Record, 54, 130-135.

Tidball, M. E. (1989). Women's colleges: Exceptional conditions, not exceptional talent, produce high achievers. In C. S. Pearson, D. L. Shavlik \& J. G. Touchton (Eds.), Educating the majority: Women challenge tradition in higher education (pp. 157-172). New York: Macmillan.

\section{Authors}

Gerd Brandell, Department of Mathematics, Luleå University of Technology, S971 87, Luleå, Sweden Email : Gerd.Brandell@sm.luth.se

Svante Carlsson, Ann-Charlotte Nord, Department of Computer Science and Engineering, Luleå University of Technology, S971 87, Luleå, Sweden.

Email: Svante.Carlsson@sm.luth.se

Håkan Ekblom, Department of Mathematics and Department of Computer Science and Engineering, Luleå University of Technology, S971 87, Luleå, Sweden.

Email: Hakan.Ekblom@sm.luth.se 